\title{
CURADORIA E LIVRO DE ARTISTA: CAMINHOS PARA UMA LEITURA DE VALÊNCIO XAVIER
}

\author{
Edma de Góis* \\ Universidade Federal da Bahia
}

Resumo: O ready-made, para Marcel Duchamp, refere-se a um objeto usual promovido a objeto de arte pela escolha deliberada do artista. O conceito, trabalhado pelo artista em texto de 1961, espera, mais que descrever um objeto, sugerir ao espectador uma experiência cerebral diante do artefato artístico. Em Minha mãe morrendo e o menino mentido (2001) vários signos de diferentes campos (tais como literatura, artes visuais, publicidade e jornalismo) circulam e são articulados a partir de um princípio de montagem, o que favorece a leitura da obra como um livro de artista, sendo o próprio autor, o curador da obra. A ideia de ready-made em consonância com a negação das formas puras pela modernidade e os limites entre as linguagens convergem na análise do livro de Valêncio Xavier (1933-2008). Neste artigo analisamos as aproximações e os distanciamentos entre imagem e texto na referida obra. Para tanto, os trabalhos de Dias (2014, 2006), Gandier (2013), Garramuño (2014) e Silveira (2008) ajudam a pensar a obra analisada a partir dos conceitos de curadoria e livro de artista, formato em que diversos campos artísticos, para além do literário, são mobilizados na produção literária contemporânea.

Palavras-chave: Livro de artista. Curadoria. Literatura brasileira contemporânea. Valêncio Xavier.

\section{Introdução}

As últimas décadas evidenciam a apropriação do hibridismo nos aportes de produção de escritores brasileiros. O que poderia não passar de um sintoma de geração e/ou época, um maior investimento na confluência entre diferentes sistemas semióticos, acaba por sugerir ao leitor a reorganização dos modos de olhar e o estranhamento no manuseio de certos romances. É o que ocorre, por exemplo, diante da obra do escritor Valêncio Xavier (1933-2008). Minha mãe morrendo e o menino mentido $(2001)^{1}$, livro em que a montagem aparece como estratégia

Esta obra está licenciada sob uma Creative Commons - Atribuição 4.0

\footnotetext{
* Pós-doutoranda (PNPD/CAPES) no Programa de Pós-Graduação em Literatura e Cultura da Universidade Federal da Bahia. Doutora em Literatura pela Universidade de Brasília e investigadora do Grupo de Estudos em Literatura Brasileira Contemporânea (Gelbc/UnB). Suas investigações recentes se relacionam com narrativas brasileiras contemporâneas, tendo como foco os problemas associados à representação e à forma nas concepções contemporâneas de arte, com ênfase no romance do século XXI. E-mail: edmagois@gmail.com.

${ }^{1}$ Ao me referir ao romance uso Minha mãe morrendo e o menino mentido ou apenas Minha mãe morrendo. Quando me refiro apenas à primeira narrativa do livro, uso "Minha mãe morrendo".
} 
formal, põe em causa uma série de preocupações teóricas pertinentes aos estudos de literatura hoje tais como as questões relativas à forma. Um dos problemas a ser analisado na produção contemporânea diz respeito a inespecificidade das obras de arte do presente.

A respeito disso, Florência Garramuño (2014, p. 7) adverte que "a estética contemporânea está habitada por uma série de práticas e intervenções artísticas que evidenciam um estendido transbordamento de limites e expansões de campos e regiões.”. A pesquisadora argentina esclarece, no entanto que "forma", no sentido por ela usado, não se refere à forma estética, uma vez que é essa categoria que é posta em questionamento pela produção artística contemporânea. Apresentando a noção de formas de não pertencimento ou de não pertinência, essa nova acepção "quer apontar mais para um modo ou dispositivo que evidencia uma condição da estética contemporânea na qual forma e especificidade parecem ser conceitos que não permitem dar conta daquilo que nela está acontecendo." (GARRAMUÑO, 2014, p. 92).

Minha mãe morrendo e o menino mentido, catalogado como "romance brasileiro", provoca as caracterizações dadas normalmente ao gênero romance ou até mesmo ao que se convencionou chamar literatura. A justaposição de textos e imagens alheias ao mundo das artes garante a reconfiguração de tais objetos na obra, tal o que propõe o ready-made duchampiano (DUCHAMP, 1961/republicado, 1966), e provoca a reflexão a respeito dos campos artísticos na contemporaneidade.

Além dos signos que ganham sentido novo na obra, Valêncio Xavier faz uso de estratégias de outras áreas, fazendo o livro transcender a sua condição de literatura. $\mathrm{O}$ efeito rítmico de cinema aparece estampado nas três narrativas que compõem o livro. Para Ângela Maranhão Gandier (2013), é notória a tentativa de reproduzir a linguagem de cinema, sendo o livro, portanto, um espaço de confluência de várias práticas com o propósito de que tais "contrabandos" formais atribuam ao texto mais significados.

De uma maneira geral, percebe-se em sua obra a imagem como eixo decisivo, o que implica na interpretação e também na originalidade dos seus livros. A leitura de suas obras, e portanto não apenas Minha mãe morrendo, como um livro de artista, acontece pelos indícios que a experiência de leitura se dá como uma visita a um museu ou a uma galeria, o que sinaliza ainda para a atividade de curadoria. Adentrar o livro pressupõe uma travessia em que estarão expostas obras de arte e obras transplantadas dos seus locais de origem para a categoria de artes diversas, dialogadas entre si, mas também autônomas. São fotos antigas, recortes de revista, atlas, livros de ciências e publicidade. O livro de artista, classificação sob 
a qual pairam interpretações dúbias desde o aparecimento das primeiras discussões sobre os suportes bibliomórficos nas artes, ainda na década de 60 do século XX, parece-nos comportar o sentido da obra de Xavier e não à toa será nosso ponto de partida.

\section{O livro de artista}

A demanda por uma classificação, não em si mesma, mas porque a partir desta podese operar determinados protocolos de leitura, aparece de modo recorrente na crítica sobre a obra de Valêncio Xavier. Ângela Maria Dias (2014, 2006) chama seus livros de "livroinvenção", aproximando-se do sentido atribuído por Haroldo de Campos à denominação "romance- invenção". Décio Pignatari refere-se à escritura de Xavier como "diagramas narrativos verbovisuais", assumindo o peso da imagem para a escrita do autor. Valêncio Xavier instaura uma estética incapaz de se resolver apenas pelo caminho do texto escrito, ao mesmo tempo em que forja significados não verossímeis, distanciando-se da representação como gesto que mimetiza o objeto representado, portanto colocando em questão a própria representação. Quando questionado sobre os usos de elementos extraliterários em seus livros, Xavier demonstrava satisfação por escrever a partir desse mosaico de imagens e chegou a assumir que só saberia contar suas histórias de modo multimodal. Na tentativa de uma classificação, podemos acrescentar ainda a ideia de ready-made, técnica que se estabelece como eixo conceitual na sua obra, ao fazer uso de fragmentos desalojados de seus lugares de origem, uma das marcas mais evidentes de sua obra.

Deslizando para o campo da crítica de artes, encontramos outros gêneros com digitais próprias, alguns deles que podem vir a agregar o texto literário em sua composição, como o livro de artista. Paulo Silveira aponta como livro de artista três tipos distintos: o livro-objeto, o livro-obra e o apenas livro, neste segmento os mais arraigados à cultura literária tradicional, adepta do código escrito. "Em todos os casos podendo ser múltiplos ou únicos, sejam ou não reclamados como obras autônomas da arte ou integrantes do corpus de uma expressão multimodal” (SILVEIRA, 2008, p. 14-15). De acordo com o pesquisador, a função do livro que é obra redefine o conceito de público em arte, considerando inclusive que os arranjos verbo-visuais constituam estratégia do artista para sua inserção no mercado cultural. Ou seja, parte-se de um princípio de arte como empreendimento ou o empreendimento como ação artística.

Valêncio Xavier propõe ao leitor um caminho de leitura de imagens e textos, uma vez que seus livros se assemelham a álbuns, livros de figurinhas e dossiês temáticos. Como veremos, desde os títulos, as narrativas analisadas parecem trazer em si uma inscrição inicial 
que tipifica os textos e solicita protocolos de leitura diferenciados, assumindo-se como livro de artista. No primeiro dos três livros que compõe o volume "Minha mãe morrendo", a narrativa é apresentada nas primeiras páginas por imagens enciclopédicas de dois olhos; o primeiro fechado, o segundo aberto, com a alternância de imagens e textos. As imagens sempre posicionadas à esquerda e os textos à direita. No primeiro momento da narrativa, o menino narrador mostra encantamento pela mãe, vista nua pela fresta da porta do banheiro. A mãe é representada à imagem de uma mulher, branca, sem pelos, cabelos aloirados e curtos, nua sobre águas, lembrando o quadro $O$ nascimento de Vênus, de Botticelli. Na sequência, o narrador recupera o sentimento de desamor e narra a segunda visão do corpo da mãe, agora no leito de hospital, seguida por duas imagens anatômicas do interior do corpo humano, provavelmente extraídas de enciclopédias de ciências. O jogo provocado pela sequência e que se realiza pelo manuseio do livro pelo leitor, ao passar as páginas, aponta ou lembra a finitude do corpo materno. O impacto provocado pelas imagens na companhia dos textos é brutal, ao ponto de a penúltima página da narrativa ser preenchida apenas por uma fotografia em que podemos ler "Senhor liberta-me das imagens" $(\mathrm{s} / \mathrm{n})$ e sobre a qual falaremos mais a frente.

Paulo Silveira (2008, p. 92) explica que é "com diminuição do uso da palavra que o livro de artista impõe sua vertente mais consistente de autonomia formal, redescobrindo a página como campo perceptivo tanto da representação como da apresentação visual”. Em Xavier percebe-se de imediato não uma redução de palavras, mas uma ocupação de páginas por elementos visuais que ilustram e são prenhes de significados, como é o caso das imagens dos olhos que abrem, fecham, e ocupam todo o livro. Outro aspecto de proximidade com o objeto das artes é o caráter cinético, encontrado sobretudo em "Minha mãe morrendo". Como adverte o pesquisador, em um produto como o livro de artista é bastante difícil eliminar o componente cinemático que surge quando folheamos o livro. O livro torna-se adstrito dos flip books ou dos flick books, to flip, do inglês, que quer dizer atirar no ar ou virar com rapidez a partir de um movimento ágil de dedos e mãos e, to flick, também do inglês, traduzido como golpear de leve, esvoaçar. Ou ainda daumenkino no alemão.

O livro de artista organiza-se de acordo com uma sequência, compreendida como uma ordem espacial e temporal, um agrupamento de formas em que cada um dos elementos está relacionado com o elemento que o antecede e ligado ao que virá a frente. Assim, todo livro visual, como o caso da obra de Valêncio Xavier, é sequencial e instaura diferentes tempos (passado, presente e futuro) a serem vivenciados por meio do contato e manejo do livro, portanto tempos reais, independente dos tempos das narrativas nele contidas. 
Vemos que a sequência narrativa em que a mãe do menino Valêncio aparece é toda entremeada por imagens, sem as quais a narrativa multimodal não se realiza. São 16 imagens, entre elas pelo menos seis fotográficas. A reflexão sobre as imagens fotográficas insinua que estamos diante de uma espécie de ocupação verbo-visual em território livresco. A obra só chega ao seu término quando da ação do leitor ou de sua colaboração como sugere Nicolas Bourriaud. O crítico diz que a obra de arte contemporânea se coloca como "local de manobras" (2009), em que narrativas são costuradas, interconectadas e prolongadas. A troca compõe o procedimento formal das artes.

É por este registro conceitual que passamos para a segunda narrativa do mesmo livro "Menino mentido - Topologia da cidade por ele habitada", definida pelo próprio autor como "uma novela em figuras" (XAVIER, 2001, p. 41). A negociação entre o artista e os leitores faz nascer a cultura do uso (BOURRIAUD, 2009). O aspecto enciclopédico do texto é uma das primeiras observações feitas ao texto, por deixar ver a mistura de sistemas imbricados.

Robert Morgan (LYONS, 1993) afirma que dois sistemas impulsionam os livros de artista, o narrativo e o concreto. A atenção dada ao livro como objeto de arte se localiza na equilibrada atenção dada a sua estrutura e ao seu conteúdo. Os sistemas narrativos podem ter um tema literário ou visual, mas não funcionam a partir de uma lógica serial, enquanto que os concretos não têm histórias mas apresentam uma organização formal. Enquanto o segundo é literal, o segundo é fecundo de significados que estão para além do texto literário. Os livros de artista podem apresentar a modelação desses sistemas propostos por Morgan, fazendo-nos entender o que cabe a cada vetor do livro, sem a preeminência do texto visual ou do texto literário.

O menino narrador apresenta a sua cidade a partir das imagens por ele comentadas. $\mathrm{O}$ prédio Martinelli, que ele via de longe no caminho para casa, serve também de referência na cidade grande. Na publicidade, o mais alto dos prédios é o assento para a jovem que usa meias Visetti: "as duas alturas máximas da América do Sul”, avisa o anúncio. As aulas de ciências são relembradas por imagens que o menino lia nos volumes de Monteiro Lobato. E assim, pouco a pouco temos uma espécie de álbum ilustrado de figurinhas de memória e percebemos melhor a informação que consta na primeira página, abaixo do subtítulo - "uma novela em figuras" (XAVIER, s/n).

Tal e qual as experiências do âmbito das artes visuais, o livro de artista de Valêncio Xavier como livro-obra é uma montagem performática e interessada. Nele, em especial, memória, história e técnicas literárias são sugeridas, mas não tomadas ao pé da letra, em 
estado bruto. Ou seja, a memória fragmentada não reivindica a memória absoluta, enquanto que a história sinalizada exige do leitor uma postura ativa na costura de sentido do texto. Já as técnicas literárias tradicionais são abandonadas em meio ao experimento verbo-visual.

Se assumirmos a impossibilidade da memória individual como defende Maurice Halbwachs (2006), o livro de artista de Xavier opera como um registro de época ou um suporte que ativa a memória coletiva de sua época, daí a importância atribuída aos anúncios publicitários e recortes de jornal, operação que é levada a uma potência ainda maior em obras como Rremembranças da menina de rua morta nua e outros livros (2006). Este mais uma vez remete à morte e o escritor artista vale-se de um arsenal midiático para a composição do livro - do mote da narrativa até a repercussão de um crime. Vale ainda observar que o livro é em si mesmo um quebra-cabeças para a recepção, ou seja, ele se constitui a partir do que é narrado sobre um episódio de violência "real" e a trama avança a partir da montagem dessa mesma narrativa. Tanto em "Minha mãe morrendo" quanto em "Rremembranças", percebe-se a anticristalização da morte, na contramão da fotografia de Roland Barthes (1984), uma vez que esta é movimentada da vida para o livro a partir da reação do leitor, forçando-o a pensar no papel da literatura frente o poder das imagens e que o atinge a sua revelia.

Portanto, embora a forma seja algo imprescindível para lermos a obra de Xavier, mais interessante do que observar os mecanismos que ativam a obra, é refletir sobre os possíveis efeitos provocados em sua leitura e o que isso tem a dizer sobre a arte contemporânea, especialmente a literatura. Valêncio Xavier é um caso exemplar para se pensar tais questões, no entanto vale ressaltar que o autor desliza em uma esteira ocupada também por outros nomes como Ignácio de Loyola Brandão, autor de Zero, cuja primeira edição surge durante a ditadura militar (a publicação é de 1975), e, para citar um caso mais recente, Luiz Ruffato e a série de livros que compõem Inferno provisório, publicada a partir de 2005. Esses autores demonstram intenção e preocupação com os leitores, as novas formas de apreensão de uma obra e as novas faces do literário. É possível ainda falar a respeito de uma nova educação do olhar, que esgarça os limites estéticos, espaciais e nacionais do sujeito da contemporaneidade.

A coerência estética e a sugestão de percurso provocado no ato de visitação da obra de Xavier como pontes de associação com o livro de artista nos leva novamente ao trabalho de Florência Garramuño, ao se referir à instalação Frutos estranhos, de Nuno Ramos (2010). Assim, ela destaca a relevância do efeito da obra para a sua compreensão: 
descrevendo a obra - a forma - e perdendo alguma coisa importante da disposição da matéria no espaço que não tem a ver com a forma estética, mas com os efeitos e afetos que essa disposição produz (GARRAMUÑO, 2014, p. 95).

Ou seja, parte do percurso que nos ajuda a compreender tais obras localiza-se nos modos de recepção que podemos lhes atribuir. É sobre o modo de olhar que devemos nos dedicar a partir de agora, compreendendo que se a forma não é mais a chave de interpretação do livro, é por outro lado reinventada cada vez que um novo olhar a observa. O jogo de imagens e textos, por exemplo, a partir de uma compreensão cinemática propõe uma narrativa visual alcançada a partir do movimento, que tem espaço e tempo como eixos elementares. E se o livro-obra nos ajuda a pensar numa retórica de publicações de artistas, a figura do curador nos auxilia na atribuição de significados que um texto multimodal poderá assumir.

\section{A curadoria}

Hans Ulrich Obrist (2014) refere-se à curadoria como sendo um ato capaz de conectar culturas e aproximar elementos comuns fazendo com que estes se toquem. Ao final de "Menino mentido - Topologia da cidade por ele habitada", uma série de instruções a maneira de notas de rodapé, porém nem sempre claras e diretas, indicam a origem de imagens utilizadas pelo autor. "Topologia tanto pode ser a mesma coisa que topografia - "Arte de representar no papel a configuração duma porção de terreno com todos os acidentes e objetos que se achem à superfície" -, como também: "Gram. Tratado da colocação ou disposição de certas espécies de palavras". Consulte o Aurélio" (XAVIER, 2001, p. 89). Ali, ele credita fotografias, nomeia livros escolares, indica museus, filmes e revistas que publicaram as publicidades citadas, assume a autoria de desenhos.

Rejane Cintrão diz que o modo como uma determinada seleção de obras é exposta denuncia a curadoria do trabalho, porque cabe a esta a realização de uma montagem que estabeleça relações formais ou conceituais entre as peças e as localize de forma estratégica no campo por ela ocupado, "onde os diálogos propostos facilitam a compreensão dos objetos expostos, ou num labirinto de ideias onde o visitante se sente perdido" (RAMOS, 2010, p. 15). Portanto, se é nossa intenção, observar os textos de Xavier como livros para visitação, o que não descarta o aspecto literário, pelo contrário, incendeia o conceito, a provocação sobre a curadoria reforça a ideia de que o autor estabelecia um modo de composição com vistas à leitura como visita guiada.

É relevante destacar que a prática de curadoria é muito mais antiga que a figura do curador e acompanha as artes tanto quanto, de modo individual, cria-se coleções íntimas ou 
arquivos (de textos, de sons, de imagens). Uma vez acionados para mostrar nossa coleção é provável que façamos uso de critérios de classificações e organização que permitam distribuir os objetos em questão no tempo e no espaço. É isso o que faz Valêncio Xavier a partir da voz de um narrador menino. Ele dispõe sua coleção particular, dispara a memória coletiva por meio de objetos apropriados de lugares extraliterários, criando narrativas já nascidas a partir de uma mediação interessada.

A terceira e última narrativa da obra "Menino Mentido" tem na figura de Lampião a sutura entre a vida real e a ficção. O narrador separa notícias de jornais, anúncios de época, trechos de diálogos com o avô, informações sobre filmes. A seleção faz bem mais que apresentar dados, como o faz de forma organizada, sendo capaz de reposicionar nossa compreensão do que é dito ou até mesmo ocultado, criando uma narrativa paralela para Lampião. O princípio ordenador de Xavier situa sua intenção a medida em que, como define Cauê Alves: "uma curadoria de arte é sempre feita a partir do que o curador selecionou e do que não selecionou, do que ele explicitou e do que não explicitou e que permanece silenciosamente no interior dos trabalhos" (RAMOS, 2010, p. 54).

A curadoria também abre portas para o entendimento não apenas de uma obra específica como de um do posicionamento do artista em dado momento, sendo esse mesmo artista o próprio produto simbólico em questão. Assim, podemos aferir que a curadoria atua na criação de uma narrativa que envolve a produção do artista, mas também dá existência à figura do autor, visto pela recepção à maneira que é sugerido pelo trabalho prático do curador. Assim, a narrativa enquadrada como autobiográfica de "Minha mãe morrendo" pode ser inserida nesse veio em que o autor-curador cria uma persona para si, independente da relação entre o mundo material e o mundo conceitual expressa na obra.

Se por um lado Lampião salta das páginas como a referência de memória do menino, cujos medos são declarados na narrativa, personagens íntimos da vida desse mesmo menino são narrados, caso da prima Clarita. O chefe do bando de sertanejos e a garota não competem nas lembranças porque cada um a sua maneira forma o narrador. Ou seja, Lampião é tão presente no imaginário do narrador quanto a menina, logo depois substituída pelas figuras femininas das histórias de Carlos Zéfiro publicadas nos anos de 1980 pela Editora Marco Zero em São Paulo. Ao final da narrativa de "Menino Mentido", Xavier repete uma de suas estratégias; credita imagens fotográficas, anúncios, desenhos e filmes, para o benefício de quem se aventurar por seu texto. A transferência de objetos para o texto literário também pode ser lida como um processo curadorial, já que um dos sentidos da curadoria é coser sentidos, 
espaços e tempos.

Ainda sobre as apropriações feitas pela arte contemporânea Nicolas Bourriaud (2009, p. 22) diz que "quando Marcel Duchamp expõe um objeto manufaturado (um porta-garrafas, um urinol, uma pá de neve...) como obra do espírito, desloca a problemática do processo criativo, colocando a ênfase não em alguma habilidade manual e sim no olhar do artista sobre o objeto". Se para Duchamp o simples ato de escolher funda a operação artística, nos casos em que o texto literário é construído da junção entre elementos escritos e visuais, pinçados de um mundo pré-existente de imagens, é incontestável um trabalho de curadoria de um livroobra.

\section{Considerações finais}

Se for possível visitar uma obra categoricamente literária, subtraindo sua pretensão literária e atentando-se ao aspecto visual do livro, possivelmente estamos diante de um bookword, um dos três tipos de livro de artista. Embora a grosso modo os mercados culturais usem livro de artista como sinônimo de "livro objeto", a definição rasteira exige um esclarecimento. O boletim Art Documentation, da Art Libraries Society of North America, de dezembro de 1982, refere-se a livro de artista como o livro em que o artista é o autor e a livro-obra como a obra de arte dependente da estrutura do livro. (SILVEIRA, 2008). As duas classificações, no entanto, no que se aproximam e se distanciam, nos ajudam a pensar na produção do escritor Valêncio Xavier, tendo por exemplo de análise as três narrativas do romance Minha mãe morrendo e o menino mentido. Por tratar-se de uma narrativa multimodal, em que sistemas semióticos diferentes são chamados a convergir (fotografia, anúncios publicitários, mapa, enciclopédias científicas etc), a obra provoca o gênero romance, exige novos protocolos de leitura e de crítica, bem como nos põe diante do questionamento acerca das possibilidades do literário e portanto da representação.

A busca por um modo de narrar a experiência de luto ou da morte promove fissuras no gênero, que logo são ocupadas por elementos visuais não ilustrativos, mas repletos de significados. $\mathrm{O}$ interesse do escritor parece por um lado construir narrativas verbo-visuais a partir de uma coleção particular e interessada e, por conseguinte, também criar um autornarrador-artista, que recebe seu estimado público desde a primeira página.

\section{Referências}

BARTHES, Roland. A câmara clara: nota sobre a fotografia. Trad. de Júlio Castañon Guimarães. Rio de Janeiro: Nova Fronteira, 1984. 
BOURRIAUD, Nicolas. Pós-produção: como a arte reprograma o mundo contemporâneo. Trad. de Denise Bottmann. São Paulo: Martins Fontes, 2009.

DIAS, Ângela Maria. Fetiches do desejo e da morte: sobre a literatura de Valêncio Xavier. Estudos de Literatura Brasileira Contemporânea, Brasília, n. 44, p. 319-330, jul/dez. 2014.

. Valêncio Xavier: o minotauro multimídia. Rio de Janeiro: Oficina Raquel, 2016.

DUCHAMP, Marcel. Sobre os ready-mades [Lecture at the Museum of Modern Art, New York, October, 19, 1961]. Publicado em: Arts and Artists, no 1, 4, julho 1966, p.47.

GANDIER, Ângela Maranhão. Memória e história, fotografia e cinema nas narrativas transemióticas de Valêncio Xavier. 2013. 182 f. Tese (Doutorado em Teoria da Literatura) Universidade Federal de Pernambuco, Recife, 2013.

GARRAMUÑO, Florência. Frutos estranhos: sobre a inespecificidade da arte contemporânea. Trad. de Paloma Vidal. Rio de Janeiro: Rocco, 2014.

HALBWACHS, Maurice. A memória coletiva. Trad. de Beatriz Sidou. São Paulo: Centauro, 2006.

LYONS, Joan. Artist's books: a critical anthology and sourcebook. Rochester: Visual Studies Workshop, 1993.

OBRIST. Hans Ulrich. Caminhos da curadoria. Trad. de Alyne Azuma. Rio de Janeiro: Cobogó, 2014.

SILVEIRA, Paulo Antônio de Menezes. As existências na narrativa no livro de artista. Tese (Doutorado no Instituto de Artes). 321 p. Universidade Federal do Rio Grande do Sul, 2008.

RAMOS, Alexandre Dias (Org.). Sobre o oficio de curador. Porto Alegre: Zouk, 2010.

XAVIER, Valêncio. Minha mãe morrendo e o menino mentido. São Paulo: Companhia das Letras, 2001.

Rremembranças da menina nua morta na rua e outros livros. São Paulo: Companhia das Letras, 2006.

Curatorship and artist's Book: ways to reading Valêncio Xavier

Abstract: The ready-made, for Marcel Duchamp, refers to an usual objet promoted to art object by the artist's deliberate choice. The concept, worked by the artist in texto of 1961, waits, more that to describe an object, to suggest to the spectator a cerebral experience before the artistic workmanship. In "Minha mãe morrendo e o menino mentido" (2001) several signs of diferente fields (such as literature, visual arts, publicity and journalism) circulate and they are articulare starting from an assembly beginning, what favors the reading of the works as an artist book, being the own author, the curator of the work. The ready-made idea in consonance with the denial in the pure ways for the modernity, the limits among the languages converge in the analysis of Valêncio Xavier'book (1933-2008). In this article we analyzed the approaches and the estrangements between image and text in the referred work. For so much, Dias' works (2014), Gandier (2013), Garramuño (2014) and Silveira (2008) they help to think the work analyzed starting from the curatorship concepts anda artist's book, format in that 
several artistic fields, for besides the literary, thet re mobilized in the contemporary literary production.

Keywords: Artist's Book. Curatorship. Contemporary Brazilian Literature. Valêncio Xavier.

Recebido em: 31/01/2018

Aceito em: 05/01/2018

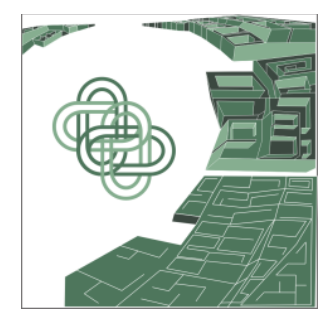

